\title{
The fate of residual aortic regurgitation after ascending aorta replacement in type $\mathrm{A}$ aortic dissection
}

Do Jung Kim, MD, ${ }^{a}$ Sak Lee, MD, PhD, ${ }^{b}$ Seung Hyun Lee, MD, PhD, ${ }^{\mathrm{b}}$ Young-Nam Youn, MD, PhD, Byung-Chul Chang, MD, PhD, ${ }^{\mathrm{c}}$ Kyung-Jong Yoo, $\mathrm{MD}, \mathrm{PhD},{ }^{\mathrm{b}}$ and Hyun-Chel Joo, MD, $\mathrm{PhD}^{\mathrm{b}}$

\section{ABSTRACT}

Objective: This study aimed to evaluate the changes in postoperative aortic regurgitation (AR) and determine the predictors of significant $A R$ and root reoperation after ascending aortic replacement (AAR) in patients with acute type $A$ aortic dissection.

Methods: From January 1995 to December 2017, 271 consecutive patients underwent valve/root-preserving AAR $(n=225)$ and root replacement $(n=46)$. AR grade trend over time was analyzed by the ordinal mixed-effects model. Significant AR was defined as AR grade $\geq 3+$ during the follow-up period. Predischarge and follow-up echocardiograms were obtained in $95.6 \%$ and $88.8 \%$ of enrolled patients, respectively.

Results: At predischarge, postoperative $\geq 2+$ AR was present in $20(9.3 \%)$ and 1 $(2.3 \%)$ patients in the AAR and root replacement groups, respectively. With increasing time after surgery, the grade of AR increased. At 10 years, $4.6 \%$ of patients had developed $3+$ or $4+$ AR. Considering death as the competing risk, the 10-year cumulative incidence of significant AR was significantly higher in the AAR than in the root replacement group $(12.3 \%$ vs $2.2 \% ; P=.047)$. The risk of root reoperation at 10 years was not different between the groups $(P=.118)$. On Cox analysis, preoperative $\geq 3+\operatorname{AR}(P=.002)$, postoperative $\geq 2+A R(P=.040)$, and false to true lumen ratio $(P=.005)$ were associated predictors of significant $A R$.

Conclusions: Although valve/root-preserving AAR demonstrated reasonable longterm outcomes when compared with root replacement, preoperative $\geq 3+A R$, postoperative $\geq 2+A R$, and high false to true lumen ratio significantly increased the risk of significant AR. Therefore, careful echocardiographic surveillance may be warranted in patients with postoperative $\geq 2+$ AR and small true lumen. ( $J$ Thorac Cardiovasc Surg 2020;160:1421-30)

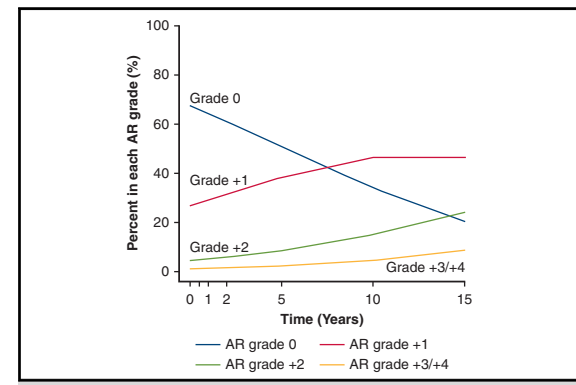

With increasing time after ascending aortic replacement, the AR grade increases.

\section{CENTRAL MESSAGE}

Higher preoperative and postoperative AR grades and high false to true lumen ratio increased the significant AR risk in patients undergoing AAR with valve/root preservation for type A aortic dissection.

\section{PERSPECTIVE}

Although valve/root-preserving AAR in AAAD showed acceptable surgical outcomes, higher preoperative and postoperative AR grades increased significant AR risk. A high postoperative FL to TL ratio also affected significant AR; therefore, both efforts to reduce the pressurized $\mathrm{FL}$ and careful echocardiogram surveillance may be warranted in patients with postoperative $\geq 2+$ AR and small TL.

See Commentaries on pages 1431 and 1432.
Despite improvements in surgical strategies and perioperative management over many years, acute type A aortic dissection (AAAD) continues to have a considerably high

From the ${ }^{a}$ Department of Thoracic and Cardiovascular Surgery, Ajou University School of Medicine, Suwon, South Korea; ${ }^{b}$ Division of Cardiovascular Surgery, Department of Thoracic and Cardiovascular Surgery, Severance Cardiovascular Hospital, Yonsei University College of Medicine, Seoul, South Korea; and ${ }^{\mathrm{c}}$ Department of Thoracic and Cardiovascular Surgery, Cha Bundang Medical Center, Cha University, Seongnam, South Korea.

Read at the 99th Annual Meeting of The American Association for Thoracic Surgery, Toronto, Ontario, Canada, May 4-7, 2019.

Received for publication May 4, 2019; revisions received Dec 18, 2019; accepted for publication Dec 20, 2019; available ahead of print Feb 26, 2020. mortality rate, ranging from $11 \%$ to $26 \% .^{1-3}$ A major concern for reducing the operative risk in patients with $\mathrm{AAAD}$ is determining the extent of resection according to 


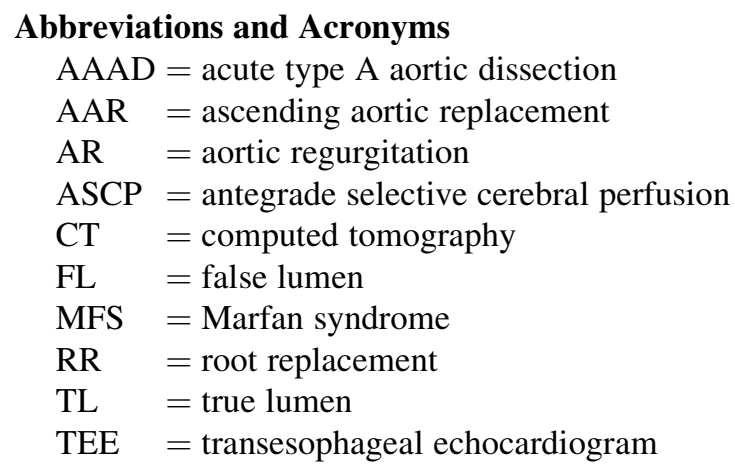

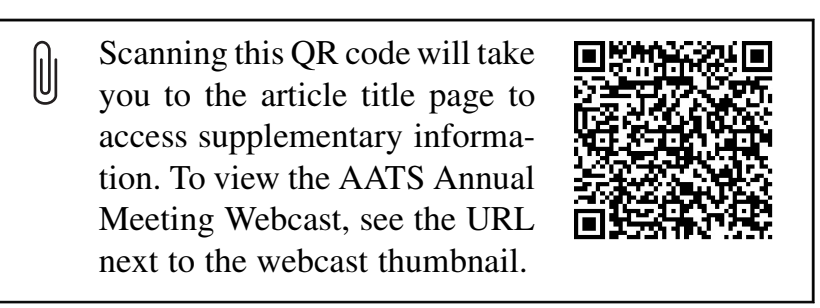

the location of the lesion and extent of the aortic involvement. Because the extension of the dissection flap into the aortic root often causes aortic regurgitation (AR) to a varying degree,$^{3-5}$ an appropriate surgical approach is important. Ascending aortic replacement (AAR) with preservation of the root and valve is the most common approach in emergency settings. ${ }^{6,7}$ However, because the dissected wall remains in the root, this procedure may result in recurrent AR or root dilatation, and subsequent root and/ or valve reoperation may be required. ${ }^{8}$

Some researchers have recently reported that extensive root surgery, such as root repair and replacement, by an experienced aortic surgeon was not associated with an increase in in-hospital mortality. ${ }^{6,9}$ However, the optimal strategy for AAAD remains controversial, and there are limited reports on predictors of significant AR and reoperation. Thus, we aimed to evaluate changes in postoperative $\mathrm{AR}$ and to determine predictors of significant $\mathrm{AR}$ after AAR with valve/root preservation in patients with AAAD.

\section{METHODS \\ Patient Selection}

From January 1995 to December 2017, 340 consecutive patients with AAAD underwent emergency surgery at the Severance Cardiovascular Hospital, Yonsei University College of Medicine. Patients who previously underwent aortic valve or root replacement (RR) or who underwent aortic surgery for iatrogenic or retrograde aortic dissection were excluded. Of all patients, $225(83 \%)$ underwent AAR with valve/root preservation (AAR group) and $46(17 \%)$ underwent RR (RR group) with composite valved graft (Bentall) or valve-sparing procedure (David). The population flowchart is shown in Figure 1.

\section{Surgical Technique}

All operations were performed on an emergency basis as soon as the diagnosis was confirmed. Standard cardiopulmonary bypass was begun based on antegrade selective cerebral perfusion (ASCP) and moderate systemic hypothermia $\left(28^{\circ} \mathrm{C}\right)$. To establish cardiopulmonary bypass, right axillary and femoral artery cannulation was used for arterial inflow and the right atrium was used for venous drainage. Unilateral ASCP through the right axillary artery was initiated by clamping the innominate artery, and the ascending aorta was opened. Bilateral ASCP was performed when the regional brain oxygen saturation decreased to $<50 \%$ with insertion of the cerebral perfusion catheter into the left carotid artery. The surgical procedure was determined based on the extent of aortic valve or root pathology, severity of AR, involvement of coronary artery through the dissected flap, and the patient's comorbidity. Indications for RR were extensive dissection of the sinuses or of the coronary artery or presence of both root dilatation $>55 \mathrm{~mm}$ and severe AR. Aortic valve-sparing RR was performed when the root and valve leaflet maintained normal geometry. All other patients underwent AAR. Even in patients with severe AR preoperatively, AAR with aortic valve resuspension and obliteration of false lumen (FL) by applying the sandwich technique was performed when the root diameter was $<55 \mathrm{~mm}$.

Once distal anastomosis was first performed using 3-0 Prolene (Ethicon, Somerville, NJ) sutures after circulatory arrest, systemic perfusion through the side branch of the graft was restored. Next, proximal anastomosis was performed during the rewarming period. The dissected aortic layers were secured with a small amount of biologic glue to reapproximate the aortic wall, and reinforcement of the dissected wall was performed using inner and outer polytetrafluoroethylene felts at the level of the sinotubular junction. The graft was then sewn to the reconstructed aortic wall using 4-0 Prolene continuous sutures (Video 1).

\section{Image Assessment and End Point}

By computed tomography (CT), we measured the diameter of ascending aorta at the midascending aorta level of pulmonary artery bifurcation and the aortic root diameter at the level of sinus of Valsalva. In the proximal descending thoracic aorta, aortic true lumen (TL) and FL diameters at the level of pulmonary artery bifurcation were measured. The degree of AR was assessed by intraoperative transesophageal echocardiogram (TEE) and by follow-up transthoracic echocardiogram before and after discharge at least once. AR severity was classified as follows: 0 (none/ trace), $1+$ (mild), 2+ (moderate), 3+ (moderately severe), and 4+ (severe). The presence of coronary artery involvement was identified by TEE.

In this study, the primary end point was change in postoperative AR over time. Secondary end points were long-term outcomes including significant $\mathrm{AR}$, root reoperation, and overall survival. Significant AR was defined as grade $\geq 3+\mathrm{AR}$ during the follow-up period, and root reoperation was defined as any surgical procedure for aortic root diameter $>55 \mathrm{~mm}$, pseudoaneurysm of the aortic root, or symptomatic severe AR. Early death was defined as death within 30 days postoperatively or during the in-hospital period.

\section{Data Collection}

Preoperative and perioperative data with clinical outcomes were prospectively collected from the cardiac and vascular research database and from the review of medical records. Survival data were collected through the Korea National Statistical Office database. Follow-up was complete for $100 \%$ of the patients with a mean duration of $8.6 \pm 5.8$ years. Most patients $(95.6 \%)$ underwent postoperative echocardiogram within 8 days before discharge. At least 1 or more follow-up echocardiograms were obtained in $88.8 \%$ of the patients with a mean follow-up duration of $7.9 \pm 6.1$ years. Moreover, postoperative CT evaluation was performed within a mean of 12.5 days in $92.6 \%$ of patients before discharge. 


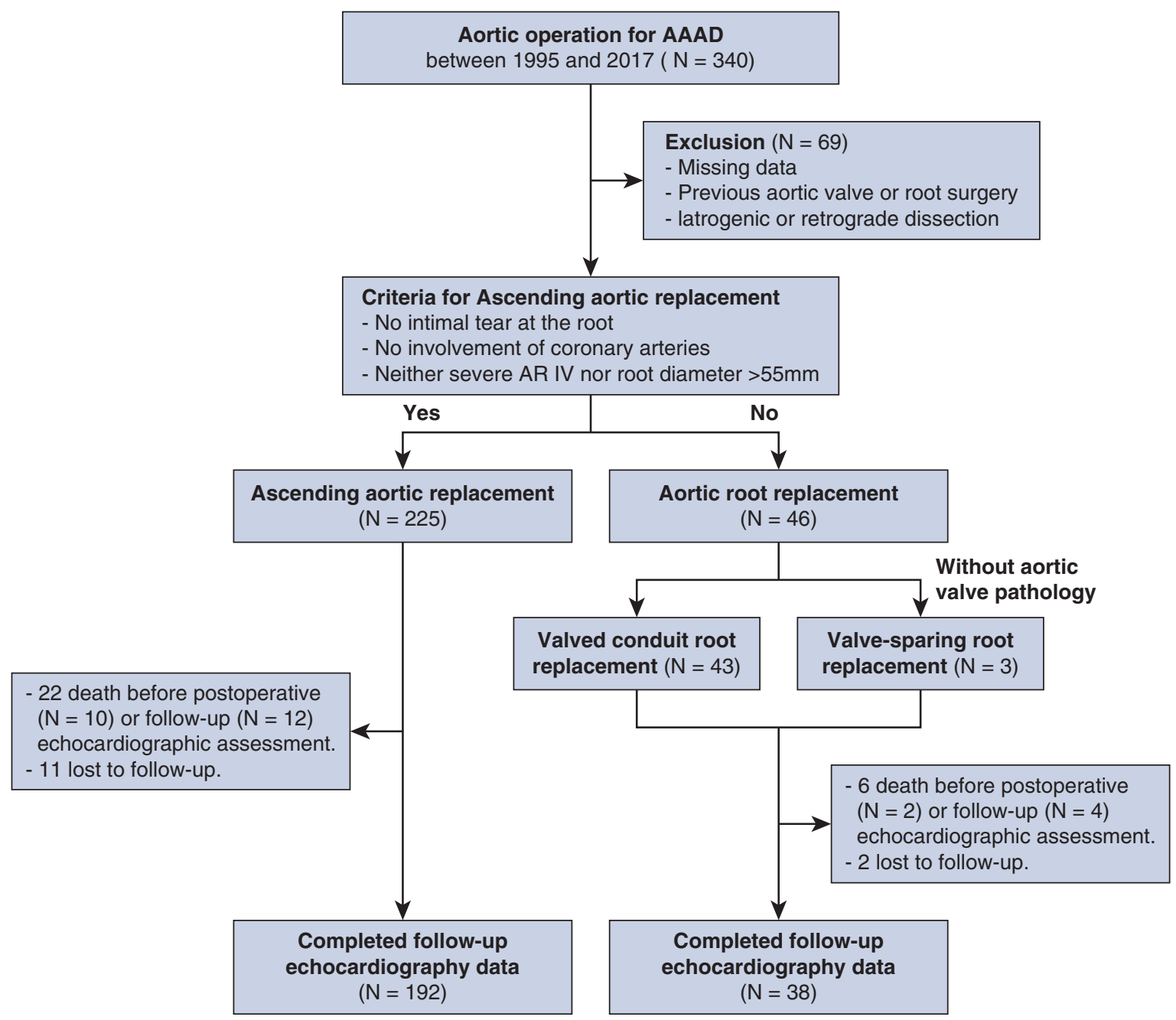

FIGURE 1. Summary flow diagram of the study population. In patients without echocardiographic data, early death was $9.8 \%$ for ascending replacement and $13.0 \%$ for root replacement. $A A A D$, Acute type A aortic dissection; $A R$, aortic regurgitation.

This study was approved by the Institutional Review Board of Yonsei University College of Medicine. Individual patient consent was waived because the study design was retrospective and there was no interference with patient treatment.

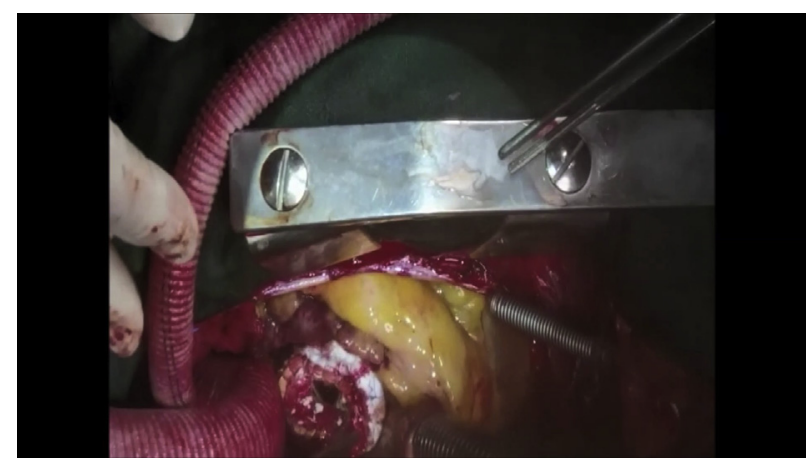

VIDEO 1. The aortic regurgitation grade decreased significantly after ascending aortic replacement in patients with acute type A aortic dissection with severe aortic regurgitation. Video available at: https://www.jtcvs.org/ article/S0022-5223(20)30431-1/fulltext.

\section{Statistical Analysis}

Statistical analyses were performed using SPSS version 23.0 (IBMSPSS Inc, Armonk, NY). All data are presented as mean \pm standard deviation or frequencies and percentages. Comparisons between variables were performed using Student $t$ test for continuous variables and the $\chi^{2}$ or Fisher exact test for categorical variables. Cumulative incidence of significant AR or root reoperation with death as a competing risk was estimated by the nonparametric method using R software (cmprsk package; R Foundation for Statistical Computing, Vienna, Austria), and the 2 groups were compared using Gray test. ${ }^{10}$ The patients who underwent reoperation were censored for AR. Ordinal mixed-effects models were used to assess the temporal trend of postoperative AR and to determine the predictors associated with AR grade over time. The model included the continuous variables of follow-up duration as a fixed effect and the subject effect as a random effect. The subject effects were assumed to be independent and have identical normal distribution (Tables E1 and E2).

Survival and freedom from significant AR were estimated by the Kaplan-Meier method with log-rank test. To determine the predictors of significant AR and root reoperation, the proportional hazards assumption was confirmed by Schoenfeld residuals test (Figure E1), but the assumption was not met. Thus, time-dependent Cox regression models were attempted. However, because there were few events for significant AR and root reoperation, we only presented the univariable analysis results. A receiver 
operating characteristic curve for the FL to TL ratio (FL:TL) was applied to measure the diagnostic accuracy over time (Figure E2) and to obtain the optimal cutoff value. All statistical tests were 2-tailed.

\section{RESULTS \\ Demographic Characteristics and Intraoperative/ Postoperative Data}

The patient characteristics are summarized in Table 1. The AAR group was older and had a less proportion of preoperative $3+$ or $4+$ AR than the RR group (both $P$ values $<.05)$. In patients with unrecognized Marfan syndrome (MFS) at the time of surgery, 8 patients $(3.6 \%)$ in the AAR group received a diagnosis of MFS postoperatively. These patients' clinical information is shown in Table E3. The mean diameters of the annulus and root were significantly smaller in the AAR group (both $P$ values <.005).

As outlined in Table 2, the RR group tended to have a higher postoperative FL:TL $(P=.058)$. Histograms of the
FL:TL are presented in Figure E3. Moreover, concomitant coronary artery bypass grafting was more commonly performed in the RR group $(19.6 \%$ vs $4.0 \% ; P<.001)$ because of right coronary ostium involvement by the intimal flap. No significant difference was found in total circulatory arrest time. Postoperative outcomes were not different between the groups.

Among 41 patients without follow-up echocardiograms, early death was $9.8 \%$ (22 out of 225 ) for AAR and $13.0 \%$ (6 out of 46 ) for RR. Of these, 5 patients had $\geq 2+$ AR on the intraoperative TEE and died of heart failure and bleeding. In the AAR group, 1 patient with $3+$ AR underwent conversion to Bentall procedure but died of right ventricle dysfunction, 2 patients with $2+$ AR refused reoperation, and 2 patients undergoing David procedure had $2+$ or $3+$ AR and failed to undergo reoperation due to high operative risk. Of the remaining 230, only 18 patients undergoing AAR had postoperative $\geq 2+$ AR.

TABLE 1. Patients' baseline characteristics

\begin{tabular}{|c|c|c|c|}
\hline Variable & Ascending aortic replacement $(n=225)$ & Root replacement $(n=46)$ & $P$ value \\
\hline Age (y) & $60.2 \pm 13.0$ & $45.8 \pm 15.6$ & $<.001$ \\
\hline Female & $119(52.9)$ & $20(43.5)$ & .245 \\
\hline Body surface area $\left(\mathrm{m}^{2}\right)$ & $1.74 \pm 0.22$ & $1.80 \pm 0.23$ & .095 \\
\hline Smoking & $64(28.4)$ & $12(26.1)$ & .746 \\
\hline Hypertension & $173(76.9)$ & $26(56.5)$ & .004 \\
\hline Diabetes mellitus & $20(8.9)$ & $3(6.5)$ & .776 \\
\hline Chronic renal failure & $54(24.0)$ & $4(8.7)$ & .021 \\
\hline Cerebrovascular accidents & $19(8.4)$ & $5(10.9)$ & .573 \\
\hline Chronic obstructive pulmonary disease & $15(6.7)$ & $3(6.5)$ & $>.999$ \\
\hline Peripheral arterial disease & $7(3.1)$ & 0 & .607 \\
\hline Coronary arterial disease & $35(15.6)$ & $2(4.3)$ & .043 \\
\hline Marfan syndrome & $8(3.6)$ & $20(43.5)$ & $<.001$ \\
\hline Cardiogenic shock & $27(12.0)$ & $5(10.9)$ & .829 \\
\hline Left ventricular ejection fraction (\%) & $62.0 \pm 10.1$ & $58.6 \pm 13.0$ & .134 \\
\hline $\begin{array}{l}\text { Aortic regurgitation grade } \\
\text { None } \\
1+ \\
2+ \\
3+ \\
4+\end{array}$ & $\begin{array}{c}103(45.8) \\
54(24.0) \\
30(13.3) \\
29(12.9) \\
9(4.0)\end{array}$ & $\begin{array}{c}2(4.3) \\
6(13.0) \\
7(15.2) \\
12(26.1) \\
19(41.3)\end{array}$ & $<.001$ \\
\hline Aortic annulus (mm) & $24.0 \pm 2.0$ & $27.4 \pm 6.0$ & .002 \\
\hline Sinus of Valsalva (mm) & $40.9 \pm 5.7$ & $52.6 \pm 14.9$ & $<.001$ \\
\hline Ascending aorta $(\mathrm{mm})$ & $53.8 \pm 10.8$ & $56.4 \pm 15.0$ & .286 \\
\hline True lumen $(\mathrm{mm})$ & $19.8 \pm 7.6$ & $20.5 \pm 9.4$ & .673 \\
\hline False lumen (mm) & $17.2 \pm 10.4$ & $15.8 \pm 10.8$ & 659 \\
\hline False/true lumen ratio & $1.22 \pm 1.14$ & $1.36 \pm 1.63$ & 638 \\
\hline
\end{tabular}

Values are presented as mean \pm standard deviation or $\mathrm{n}(\%)$. 
TABLE 2. Intraoperative and postoperative data

\begin{tabular}{|c|c|c|c|}
\hline Variable & Ascending aortic replacement $(\mathbf{n}=\mathbf{2 2 5})$ & Root replacement $(n=46)$ & $P$ value \\
\hline \multicolumn{4}{|l|}{ Intraoperative data } \\
\hline Distal repair & & & .791 \\
\hline Hemiarch replacement & $168(74.7)$ & $33(71.7)$ & \\
\hline Partial arch replacement & $22(9.8)$ & $4(8.7)$ & \\
\hline Total arch replacement & $35(15.6)$ & $9(19.6)$ & \\
\hline \multicolumn{4}{|l|}{ Concomitant procedures } \\
\hline Coronary artery bypass graft & $9(4.0)$ & $9(19.6)$ & $<.001$ \\
\hline Mitral valve repair & $3(1.3)$ & $5(10.9)$ & .004 \\
\hline Tricuspid valve repair & $3(1.3)$ & $1(2.2)$ & .527 \\
\hline Cardiopulmonary bypass time (min) & $201.3 \pm 73.2$ & $293.4 \pm 110.9$ & $<.001$ \\
\hline Aortic crossclamp time (min) & $118.2 \pm 50.2$ & $189.7 \pm 76.4$ & $<.001$ \\
\hline Total circulatory arrest time (min) & $44.5 \pm 24.9$ & $44.2 \pm 37.9$ & .963 \\
\hline \multicolumn{4}{|l|}{ Postoperative data } \\
\hline Reoperation for bleeding & $23(10.2)$ & $8(17.4)$ & .164 \\
\hline Stroke & $19(8.4)$ & $2(4.3)$ & .545 \\
\hline Prolonged ventilation $(>72 \mathrm{~h})$ & $65(28.9)$ & $10(21.7)$ & .323 \\
\hline Newly required dialysis & $17(7.6)$ & $5(10.9)$ & .551 \\
\hline In-hospital mortality & $20(8.9)$ & $6(13.0)$ & .410 \\
\hline Aortic regurgitation grade & $\mathrm{n}=215$ & $\mathrm{n}=44$ & .012 \\
\hline None & $155(72.1)$ & $42(95.5)$ & \\
\hline $1+$ & $40(18.6)$ & $1(2.3)$ & \\
\hline $2+$ & $18(8.4)$ & $1(2.3)$ & \\
\hline $3+$ & $2(0.9)$ & 0 & \\
\hline Aortic annulus (mm) & $24.1 \pm 1.9$ & $24.6 \pm 2.6$ & .231 \\
\hline Sinotubular junction (mm) & $31.6 \pm 3.0$ & $28.1 \pm 3.1$ & $<.001$ \\
\hline True lumen $(\mathrm{mm})$ & $22.1 \pm 8.0$ & $19.2 \pm 8.4$ & .055 \\
\hline False lumen (mm) & $14.4 \pm 10.4$ & $17.9 \pm 16.0$ & .214 \\
\hline False/true lumen ratio & $0.94 \pm 1.00$ & $1.47 \pm 1.53$ & .058 \\
\hline
\end{tabular}

Values are presented as mean \pm standard deviation or $\mathrm{n}(\%)$

\section{Long-Term Outcomes}

During follow-up, there were 21 late deaths (16 in AAR and 5 in RR). The 10-year overall survival was $82.1 \% \pm 3.1 \%$ for $\mathrm{AAR}$ and $81.2 \% \pm 6.1 \%$ for $\mathrm{RR}$ (log-rank $P=.756$ ) (Figure E4).

\section{AR Grade Over Time and Significant AR}

In the mixed-effects model, with increasing time after surgery, the incidence of higher AR grade increased (Figure 2). At 10 years, $15.1 \%$ of patients had developed $2+\mathrm{AR}$ and $4.6 \%$ of the patients had developed $3+$ or $4+$ AR. Longer duration, older age, and greater root diameter were significantly associated with increased AR grade over time. FL:TL, as calculated from the first postoperative CT findings, was also an associated predictor for AR grade over time (Table E2). Furthermore, severity of regurgitation increased rapidly with higher preoperative and postoperative AR grade. Figure 3, $A$ and $B$, shows that patients with preoperative $3+$ or $4+\mathrm{AR}$ and postoperative $\geq 2+\mathrm{AR}$ were more likely to have higher AR grade than patients without those conditions.

However, the RR group was excluded from this analysis. Because patients who underwent the Bentall procedure had no change in AR grade and only 3 patients underwent the David procedure, the data were too less for analysis. Considering death as the competing risk, the 10-year cumulative incidence of significant AR was higher in the AAR than in the RR group $(12.3 \%$ vs $2.2 \% ; P=.047)$ (Figure 4, $A$ ).

\section{Root Reoperation}

Thirteen patients underwent root reoperations using the Bentall procedure. The indications for reoperations were severe $\operatorname{AR}(n=6)$, root dilatation with $\operatorname{AR}(n=5)$, and pseudoaneurysm $(\mathrm{n}=2)$. The 10-year cumulative incidence of root reoperation with death as the competing risk was $8.1 \%$ for AAR and $0 \%$ for RR, with no significant difference between the groups $(P=.118)$ (Figure $4, B)$. Distal aortic reintervention included 13 arch replacements, 11 descending thoracic replacements, 7 thoracoabdominal replacements, and 20 stent grafts. Of these, 12 patients underwent 2 or more procedures.

\section{Predictors for Significant AR and Root Reoperation}

In the time-dependent Cox analyses, the associated predictors for significant $\mathrm{AR}$ were preoperative $\geq 3+\mathrm{AR}$, 


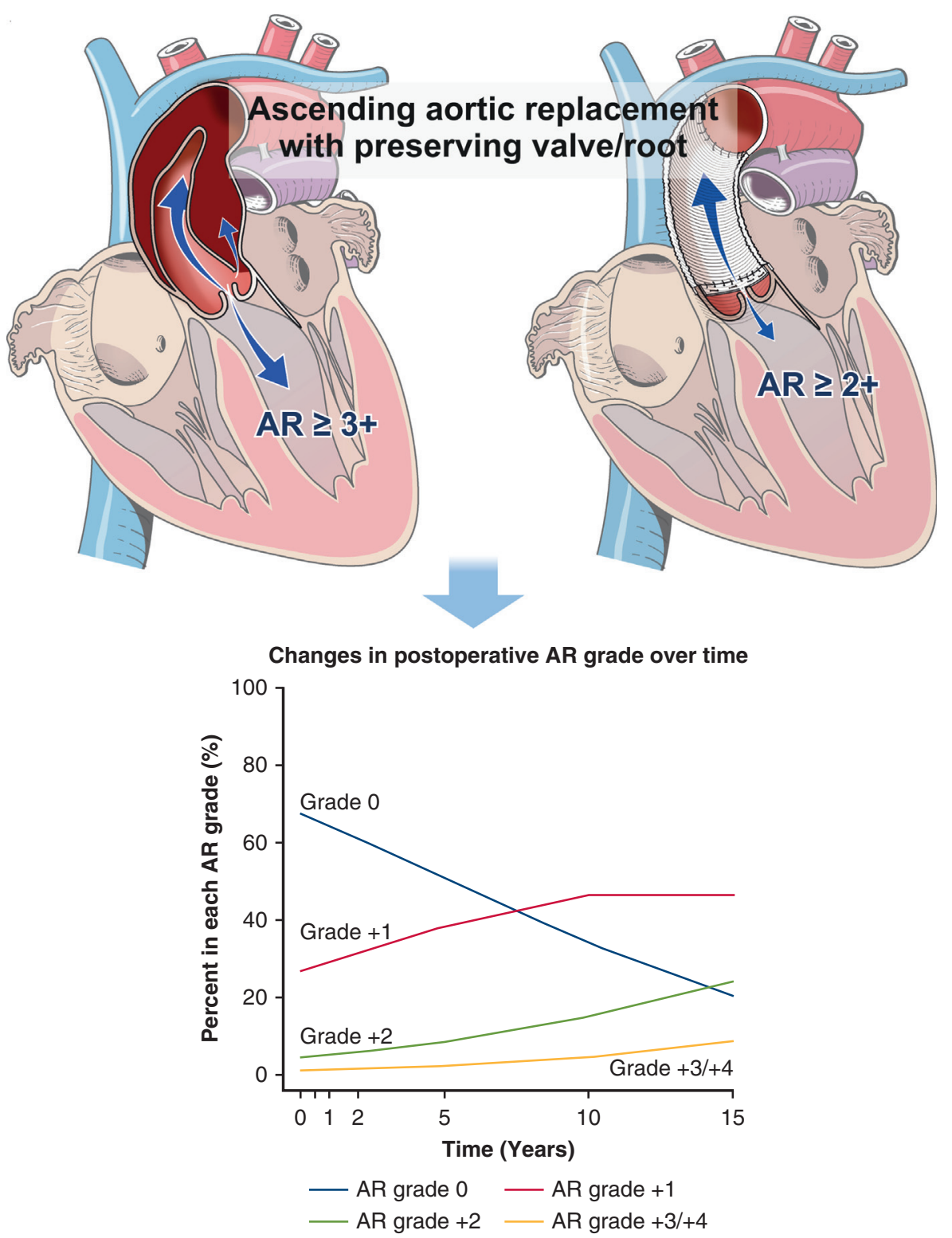

FIGURE 2. After surgery of ascending aortic replacement in patients with acute type A aortic dissection, high preoperative or postoperative aortic regurgitation $(A R)$ is significantly associated with increased AR grade over time.

postoperative $\geq 2+\mathrm{AR}$, and postoperative FL:TL (all $P$ values $<.05$ ) (Table 3 ). The freedom from significant $A R$ was significantly lower in patients with high preoperative or postoperative AR grade (Figure 5, $A$ and $B$ ). When applying the optimal cutoff value for FL:TL, the 10-year freedom from significant AR was also lower in patients with a ratio $\geq 1.5(65.1 \% \pm 10.0 \%$ vs $95.6 \% \pm 2.5 \%$; $P<.001$ ) (Figure 5, $C$ and $D$ ). Additionally, younger age and larger root were predictors of root reoperation.

\section{DISCUSSION}

In this study, the majority of patients with preoperative AR showed significant improvement after AAR with valve/root preservation. However, in some patients, the AR persisted postoperatively, and this factor affected significant AR. In addition, higher preoperative and postoperative AR grade and high FL:TL were predictors of significant AR and AR grade over time.

Although refinements in the surgical techniques and perioperative care over time have been made for patients with $\mathrm{AAAD}$, the risk of mortality and morbidity following emergency surgery remains high. To prevent aortic rupture and to keep the patient alive, central repair through AAR with sinotubular reinforcement may be commonly performed, but this procedure has been reported to have a relative risk of late reoperation. ${ }^{11,12}$ Meanwhile, more extensive 

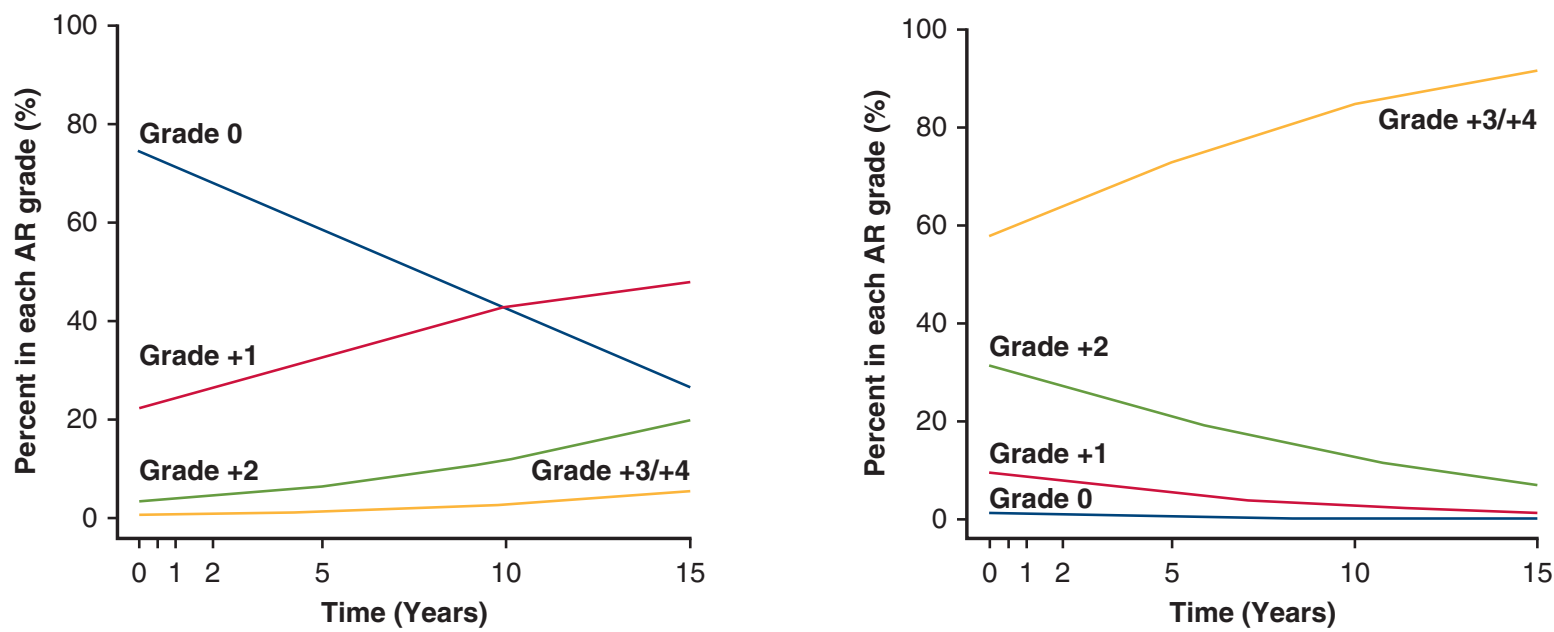

\begin{tabular}{|c|c|c|c|c|}
\hline Time & 0 & 5 & 10 & 15 \\
\hline None & 74.03 & 58.92 & 41.92 & 26.65 \\
\hline $1+$ & 21.77 & 33.05 & 43.30 & 47.73 \\
\hline $2+$ & 3.46 & 6.56 & 11.90 & 20.06 \\
\hline $3+/ 4+$ & 0.75 & 1.47 & 2.88 & 5.57 \\
\hline
\end{tabular}

\begin{tabular}{rcccc} 
Time & 0 & 5 & 10 & 15 \\
\hline None & 1.43 & 0.73 & 0.37 & 0.19 \\
$1+$ & 9.27 & 4.96 & 2.58 & 1.32 \\
$\mathbf{2 +}$ & 31.36 & 21.1 & 12.59 & 6.97 \\
$3+/ 4+$ & 57.94 & 73.24 & 84.47 & 91.53 \\
\hline \multicolumn{4}{c}{ AR grade 0 } & AR grade +1 \\
& & AR grade +2 & AR grade $+3 /+4$
\end{tabular}

A

B

FIGURE 3. Changes in postoperative aortic regurgitation $(A R)$ grade over time after adjusting for male patients of mean age with mean root diameter and false to true lumen ratio. A, Patients with both preoperative $<3+$ AR and postoperative $<2+$ AR. B, Patients with preoperative $\geq 3+$ AR and postoperative $\geq 2+\mathrm{AR}$.
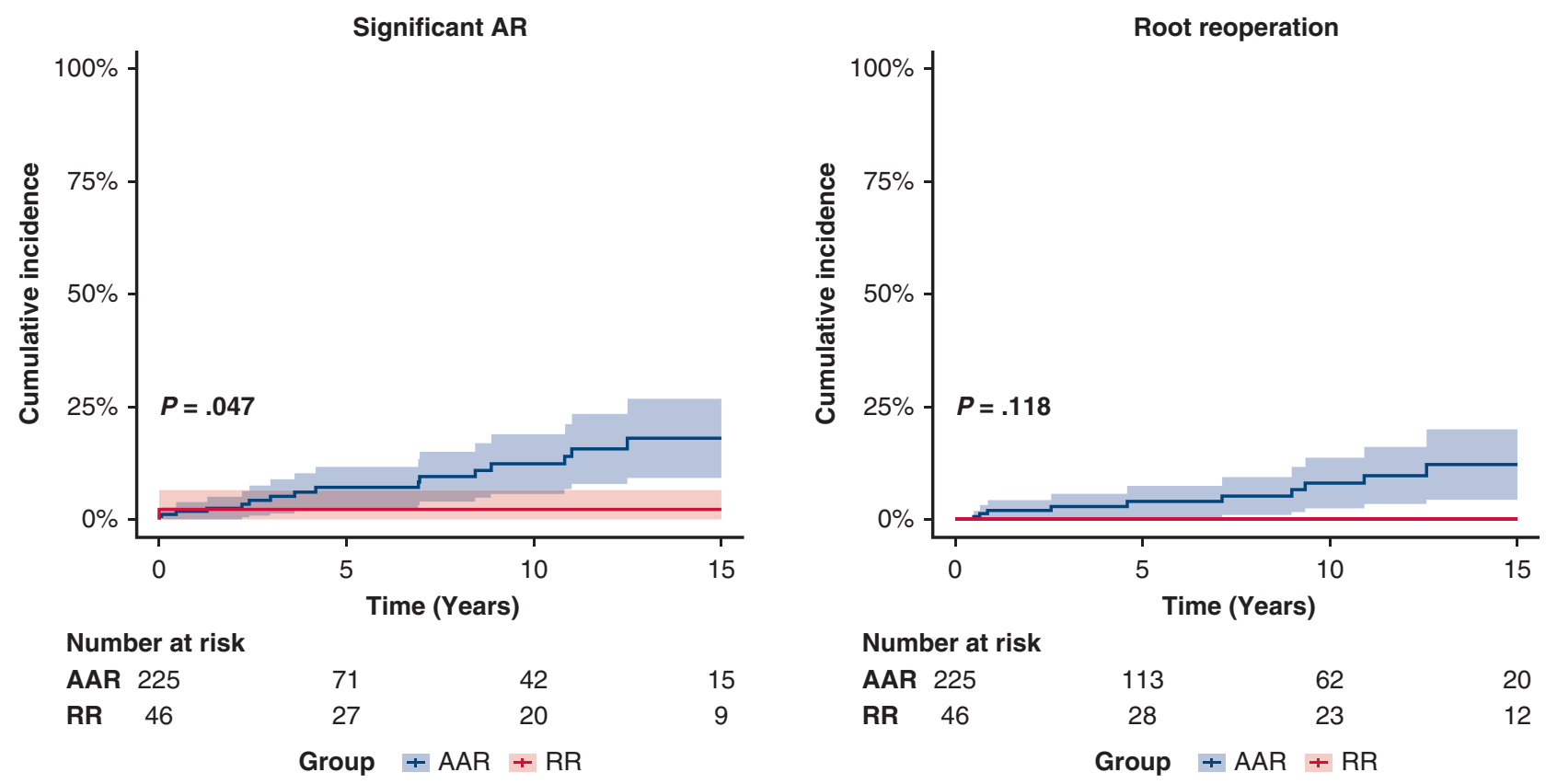

A

B

FIGURE 4. Considering death as the competing risk, the cumulative incidence (A) for significant aortic regurgitation $(A R)$ and $(\mathrm{B})$ root reoperation $(R R)$ between the groups. $A A R$, Ascending aortic replacement. 
TABLE 3. Associated predictors for significant aortic regurgitation (AR) and root reoperation by Cox regression analysis

\begin{tabular}{llr}
\hline \multicolumn{1}{c}{ Variable } & $\begin{array}{c}\text { Hazard ratio }(\mathbf{9 5} \% \\
\text { confidence interval) }\end{array}$ & $\boldsymbol{P}$ value \\
\hline Significant AR & & \\
Pre-AR grade $\geq 3+$ & $7.024(2.598-18.986)$ & $<.001$ \\
Post-AR grade $\geq 2+$ & $4.365(1.376-13.846)$ & .002 \\
False/true lumen ratio & $2.221(1.429-3.453)$ & $<.001$ \\
Root reoperation & & \\
Age (y) & $0.908(0.863-0.955)$ & $<.001$ \\
Post-AR grade $\geq 2+$ & $4.818(1.227-18.922)$ & .024 \\
Sinus of Valsalva & $1.121(1.071-1.173)$ & $<.001$ \\
False/true lumen ratio & $2.325(1.406-3.844)$ & .001 \\
\hline
\end{tabular}

$A R$, Aortic regurgitation.

aortic root surgeries such as root repair or replacement may prevent late aneurysm formation and recurrent dissection of the aortic root or worsening of the AR, but they remain controversial. $^{8,13}$ At our institute, most patients with AAAD undergo AAR with valve/root preservation, whereas patients with both root dilatation $>55 \mathrm{~mm}$ and severe AR or those with existing intimal tear at the aortic root and coronary arteries are considered for RR.

In addition, we focused on the fate of untreated AR in patients with AAAD. Varying degrees of AR are caused by retrograde extension of the dissection, involvement of the sinus segment, and downward displacement of normal aortic leaflets into the left ventricle. ${ }^{5}$ When there was no obvious valvular pathology, AAR with restoration of the integrity of valve competence was performed even in patients with preoperative severe AR, and postoperative AR was dramatically reduced in this study. However, in some cases, AR did not regress despite correction of the dissection and persisted postoperatively in 20 patients $(9.3 \%)$. Paulis and colleagues ${ }^{14}$ have reported that residual AR reflects insufficient adhesion and fixation of the dissected layers. Moreover, Luciani and colleagues ${ }^{15}$ reported that the normal looking root and valve at the time of initial operation may be actually abnormal in patients who subsequently progress to AR. These findings are somewhat consistent with our results. Significant AR was observed during follow-up in $27.8 \%$ and $22.2 \%$ of patients who were postoperatively diagnosed with valvular pathology and connective tissue disease, respectively. These results imply that it is important to consider the patient-related factors when determining the initial surgical approach.

Although previous reports demonstrated preoperative severe $\mathrm{AR}$ as a risk factor for progressive $\mathrm{AR},{ }^{16,17}$ it has not been reported exactly how the postoperative residual regurgitation changes during follow-up. Our results showed that the risk of significant AR increases when postoperative regurgitation remains. Therefore, we should keep in mind that if $\mathrm{AR}$ remains upon bypass weaning in the operating room or if there is residual $\geq 2+A R$ upon predischarge transthoracic echocardiogram, AR may gradually proceed and the reoperation rate may increase. Additionally, if the life expectancy, surgical risk, and emergency status are acceptable, we highly recommend the extensive root surgery for reoperation. Careful echocardiographic surveillance to assess the aortic valvular function and efforts to reduce AR severity are also warranted.

In our findings, high preoperative and postoperative AR grades were identified as an associated predictor of significant AR, but the incidence of root events was low and distal reintervention was more common. High FL:TL was also an important risk factor for significant AR. The exact cause of these findings is unknown, but it is well known that pressurized FL in the descending thoracic aorta is a major cause of aortic dilatation. ${ }^{18}$ In a recent study published by Suzuki and colleagues, ${ }^{19}$ they measured FL and TL diameters on postoperative CT and reported that false lumen to true lumen index $>1$ was an important predictor of late proximal and distal reoperation. We believe that a high FL:TL may reflect unfavorable aortic remodeling because FL due to the residual dissected aorta remains patent, and then pressurized FL increases the afterload, which may have cause root dilatation or AR. Therefore, reintervention to FL, such as endovascular stent and reoperation on the distal aorta, and vasodilator therapy reducing aortic dilatation and afterload may help enhance the forward flow of TL.

Moreover, many factors that potentially affect late root reoperation following AAR include severity of $\mathrm{AR}$, root dilatation, involvement of the coronary arteries, presence of known aortic diseases (eg, annuloectasia or MFS), and dissection of all the aortic sinuses. ${ }^{6,12,20}$ In this study, young age and root dilatation were associated with increases in proximal reoperation rates. Similar to those of previously reported studies, ${ }^{6,11}$ these results may be explained by the fact that extensive root surgery in young patients with a large aortic root may reduce the risk of future root reoperation.

This study has several limitations. First, it was a singlecenter retrospective study. Although only AAAD patients were enrolled in this study, the presence of selection bias cannot be ruled out because the characteristics of the 2 groups (including incidence of MFS, age, and FL:TL) were biologically different. It is difficult to generalize conclusions about the clinical outcome by surgical intervention alone. Second, although some patients had long-term follow-up, only 192 patients had echocardiographic data available for analysis. The relatively small sample size of patients undergoing RR was insufficient to ensure statistically robust inferences; therefore, the reoperation prevalence between the groups may have been underestimated. Third, due to the very small number of events, we presented only the time-dependent univariable 

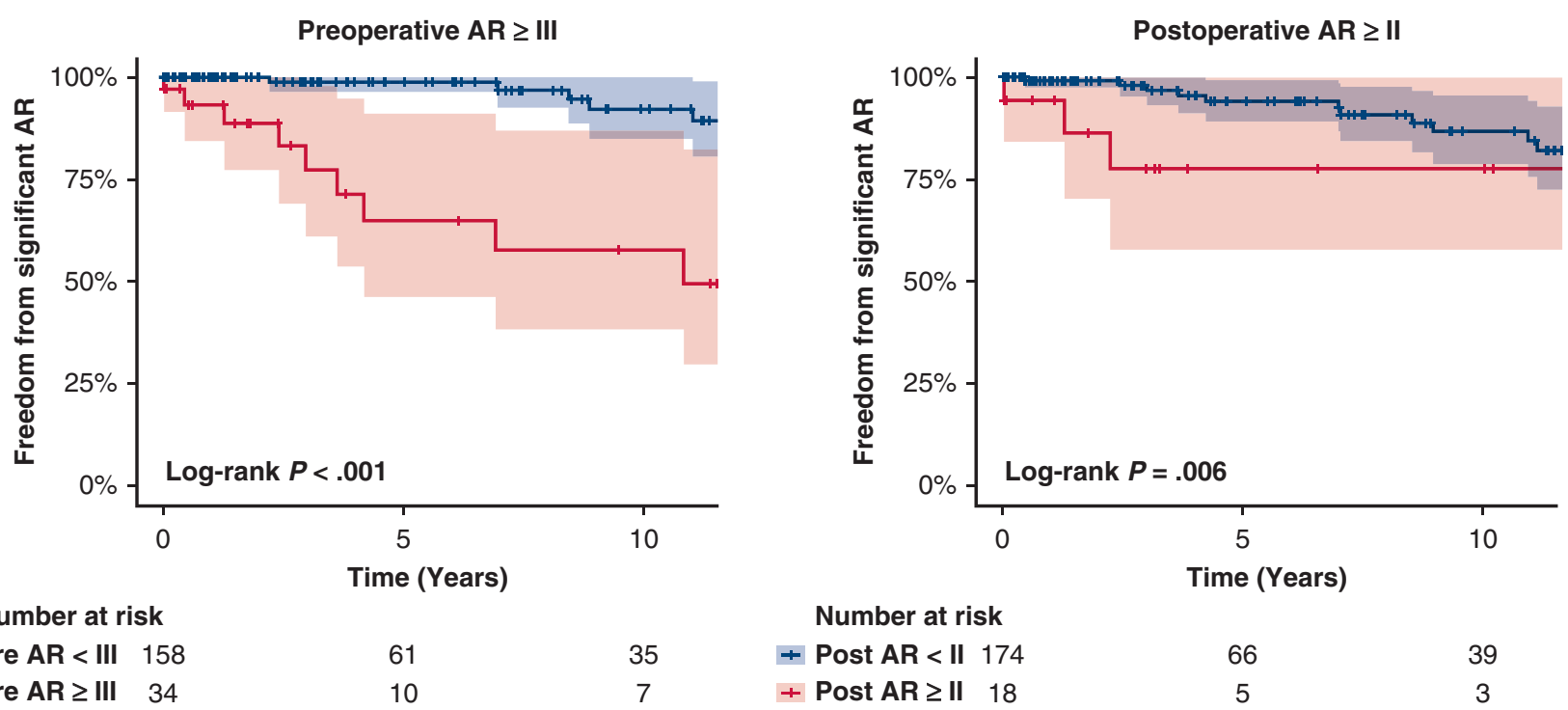

Number at risk

+ Pre AR < III 158

61

10

35

A

B

FL/TL ratio $\geq 1.5$
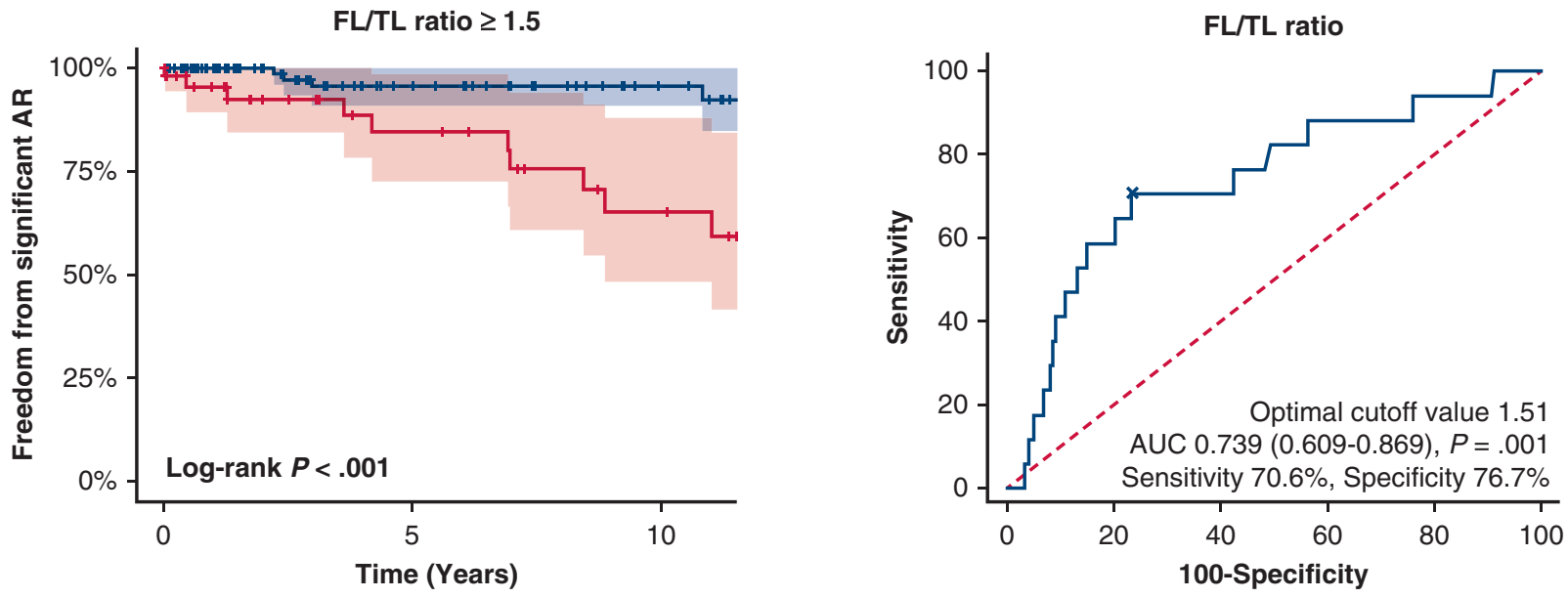

Number at risk

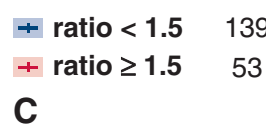

$50 \quad 30$

$21 \quad 12$

FIGURE 5. Kaplan-Meier curves comparing freedom from significant aortic regurgitation ( $A R$ ) according to (A) preoperative $\geq 3+$ AR, (B) postoperative $\geq 2+\mathrm{AR}$, and $(\mathrm{C})$ ratio $\geq 1.5$. D, Receiver operating characteristic curve for false lumen to true lumen ratio (FL/TL ratio) as predictor of significant AR. The optimal cutoff value of the ratio was 1.51. AUC, Area under the curve.

Cox models because multivariable models were too unstable to identify predictors for significant AR and reoperation. A large-scale, prospective study is necessary to confirm our findings in the setting of emergency surgery. Finally, factors such as surgeons' experience, surgical strategies, and postoperative use of medication may have influenced the long-term outcomes. However, considering patient-specific and aortic pathologic factors, we believe that rapid judgment and choice of the appropriate surgical procedure are paramount to saving the lives of patients in an emergency situation.

\section{CONCLUSIONS}

In patients with $\mathrm{AAAD}, \mathrm{AAR}$ with valve/root preservation showed good surgical outcomes. We found that preoperative $3+$ or $4+\mathrm{AR}$ and postoperative $\geq 2+\mathrm{AR}$ were important risk factors for significant AR. Additionally, a high postoperative FL:TL can induce AR or root dilatation, which may be a predictor of significant AR. Therefore, both efforts to reduce the pressurized FL and careful echocardiographic surveillance to assess the aortic valve function may be warranted in patients with postoperative $\geq 2+\mathrm{AR}$ and small TL. 


\section{Webcast}

You can watch a Webcast of this AATS meeting presentation by going to: https://aats.blob.core.windows.net/media/ 19\%20AM/Monday_May6/206E/206E/S82\%20-\%20Rap id $\% 20$ fire $\% 20$ abstracts $\% 20$ V/S82_11_webcast_0255548 46.mp4.

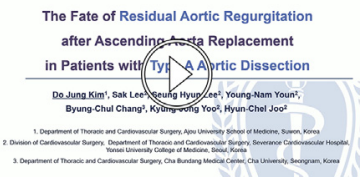

\section{Conflict of Interest Statement}

Authors have nothing to disclose with regard to commercial support.

The authors thank Woohyun Cho, Ajou Medical Information \& Media Center, for valuable contributions to creation of the figures, and Dong-su Jang, Medical Research Support Services, Yonsei University College of Medicine, for helping design the graphical abstract. The authors also thank Bumhee Park, PhD, and Han-Bit Shin, MS, from the Office of Biostatistics, Ajou Research Institute for Innovation Medicine, and Myeong Jee Lee, from the Biostatistics Collaboration Unit, Yonsei University College of Medicine, for giving advice and practical help in the statistical analysis.

\section{References}

1. Pape LA, Awais M, Woznicki EM, Suzuki T, Trimarchi S, Evangelista A, et al Presentation, diagnosis, and outcomes of acute aortic dissection: 17-year trends from the international registry of acute aortic dissection. J Am Coll Cardiol. 2015;66:350-8.

2. Berretta P, Patel HJ, Gleason TG, Sundt TM, Myrmel T, Desai N, et al. IRAD experience on surgical type A acute dissection patients: results and predictors of mortality. Ann Cardiothorac Surg. 2016;5:346-51.

3. Rylski B, Bavaria JE, Milewski RK, Vallabhajosyula P, Moser W, Kremens E, et al. Long-term results of neomedia sinus of Valsalva repair in 489 patients with type A aortic dissection. Ann Thorac Surg. 2014;98:582-8.

4. Movsowitz HD, Levine RA, Hilgenberg AD, Isselbacher EM. Transesophageal echocardiographic description of the mechanisms of aortic regurgitation in acute type A aortic dissection: implications for aortic valve repair. J Am Coll Cardiol. 2000:36:884-90

5. Patel PA, Bavaria JE, Ghadimi K, Gutsche JT, Vallabhajosyula P, Ko HA, et al Aortic regurgitation in acute type-a aortic dissection: a clinical classification for the perioperative echocardiographer in the era of the functional aortic annulus. J Cardiothorac Vasc Anesth. 2018:32:586-97.

6. Di Eusanio M, Trimarchi S, Peterson MD, Myrmel T, Hughes GC, Korach A, et al. Root replacement surgery versus more conservative management during type A acute aortic dissection repair. Ann Thorac Surg 2014;98:2078-84.

7. Halstead JC, Spielvogel D, Meier DM, Rinke S, Bodian C, Malekan R, et al. Composite aortic root replacement in acute type A dissection: time to rethink the indications? Eur J Cardiothorac Surg. 2005;27:626-32.

8. Concistre G, Casali G, Santaniello E, Montalto A, Fiorani B, Dell'Aquila A, et al Reoperation after surgical correction of acute type A aortic dissection: risk factor analysis. Ann Thorac Surg. 2012;93:450-5.

9. Wang Z, Greason KL, Pochettino A, Schaff HV, Suri RM, Stulak JM, et al. Longterm outcomes of survival and freedom from reoperation on the aortic root or valve after surgery for acute ascending aorta dissection. $J$ Thorac Cardiovasc Surg. 2014;148:2117-22

10. Gray RJ. A class of \$ K \$-sample tests for comparing the cumulative incidence of a competing risk. Ann Stat. 1988;16:1141-54.

11. Dell'Aquila AM, Concistre G, Gallo A, Pansini S, Piccardo A, Passerone G, et al. Fate of the preserved aortic root after treatment of acute type A aortic dissection: 23-year follow-up. J Thorac Cardiovasc Surg. 2013;146:1456-60.

12. Rylski B, Beyersdorf F, Blanke P, Boos A, Hoffmann I, Dashkevich A, et al Supracoronary ascending aortic replacement in patients with acute aortic dissection type A: what happens to the aortic root in the long run? J Thorac Cardiovas Surg. 2013;146:285-90.

13. Lai DT, Miller DC, Mitchell RS, Oyer PE, Moore KA, Robbins RC, et al. Acute type A aortic dissection complicated by aortic regurgitation: composite valve graft versus separate valve graft versus conservative valve repair. J Thorac Cardiovasc Surg. 2003;126:1978-86

14. De Paulis R, Cetrano E, Moscarelli M, Ando G, Bertoldo F, Scaffa R, et al. Effects of ascending aorta replacement on aortic root dilatation. Eur J Cardiothorac Surg. 2005;27:86-9.

15. Luciani GB, Casali G, Tomezzoli A, Mazzucco A. Recurrence of aortic insuffi ciency after aortic root remodeling with valve preservation. Ann Thorac Surg. 1999;67:1849-52

16. Pessotto R, Santini F, Pugliese P, Montalbano G, Luciani GB, Faggian G, et al Preservation of the aortic valve in acute type A dissection complicated by aortic regurgitation. Ann Thorac Surg. 1999;67:2010-3.

17. Tang PC, Badami A, Akhter SA, Osaki S, Lozonschi L, Kohmoto T, et al. Efficacy of aortic valve resuspension in establishing valve competence in acute type A dissections. Ann Thorac Surg. 2017;103:1460-6.

18. Song SW, Chang BC, Cho BK, Yi G, Youn YN, Lee S, et al. Effects of partia thrombosis on distal aorta after repair of acute DeBakey type I aortic dissection. J Thorac Cardiovasc Surg. 2010;139:841-7.e1.

19. Suzuki T, Asai T, Kinoshita T. Predictors for late reoperation after surgical repair of acute type A aortic dissection. Ann Thorac Surg. 2018;106:63-9.

20. Ro SK, Kim JB, Hwang SK, Jung SH, Choo SJ, Chung CH, et al. Aortic root conservative repair of acute type A aortic dissection involving the aortic root: fate of the aortic root and aortic valve function. J Thorac Cardiovasc Surg. 2013;146: $1113-8$.

Key Words: aortic dissection, aortic valve insufficiency 

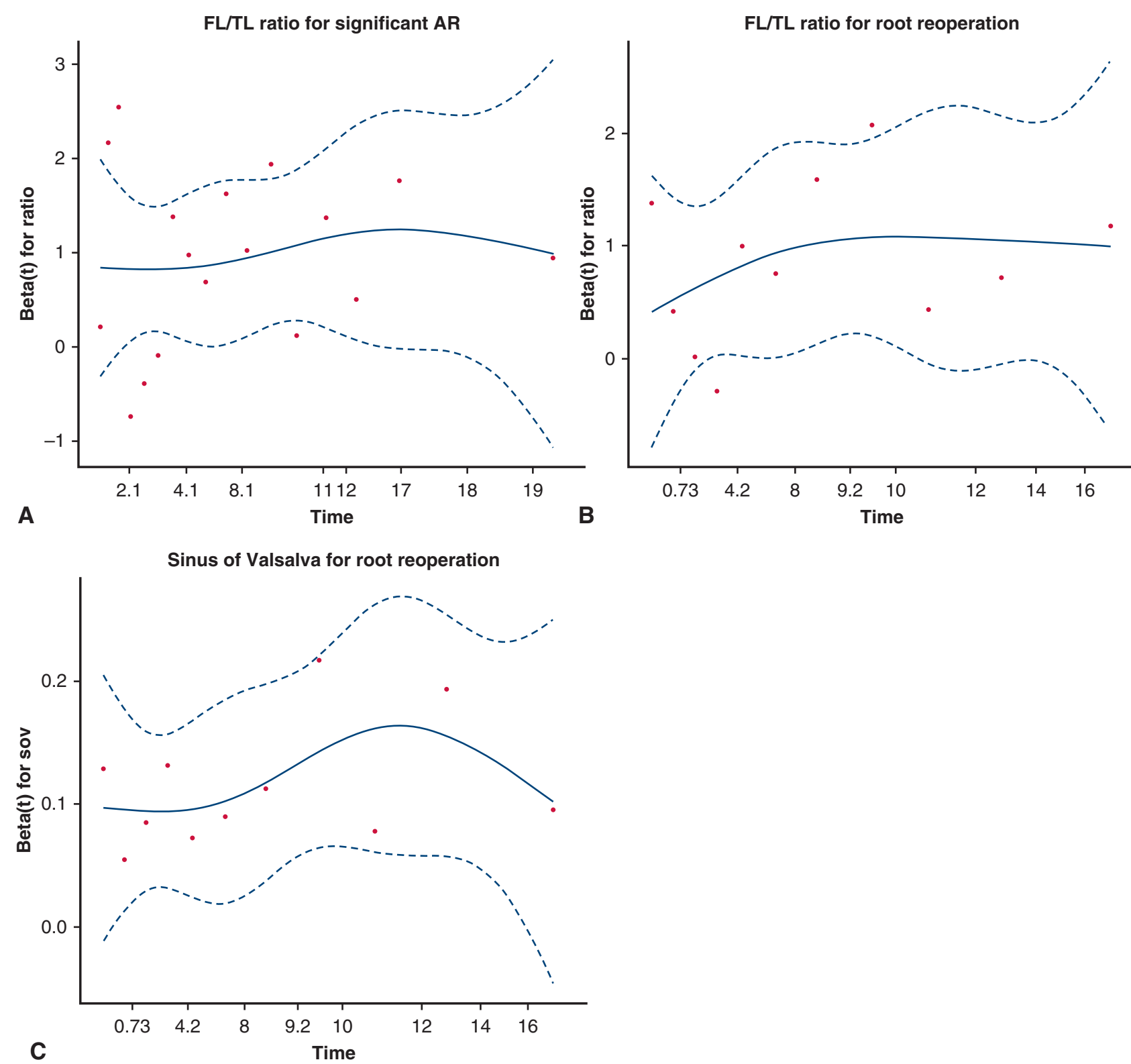

FIGURE E1. A, Cox proportional hazards $(\mathrm{PH})$ assumptions of postoperative false lumen to true lumen ratio (FL/TL ratio) and diameter of sinus of Valsalva for significant aortic regurgitation $(A R)$. B and C, Assumptions for the root reoperation were confirmed by Schoenfeld residuals test. Based on the graphical inspection, a non-0 slope is an indication of a violation of the $\mathrm{PH}$ assumption for the covariates. 

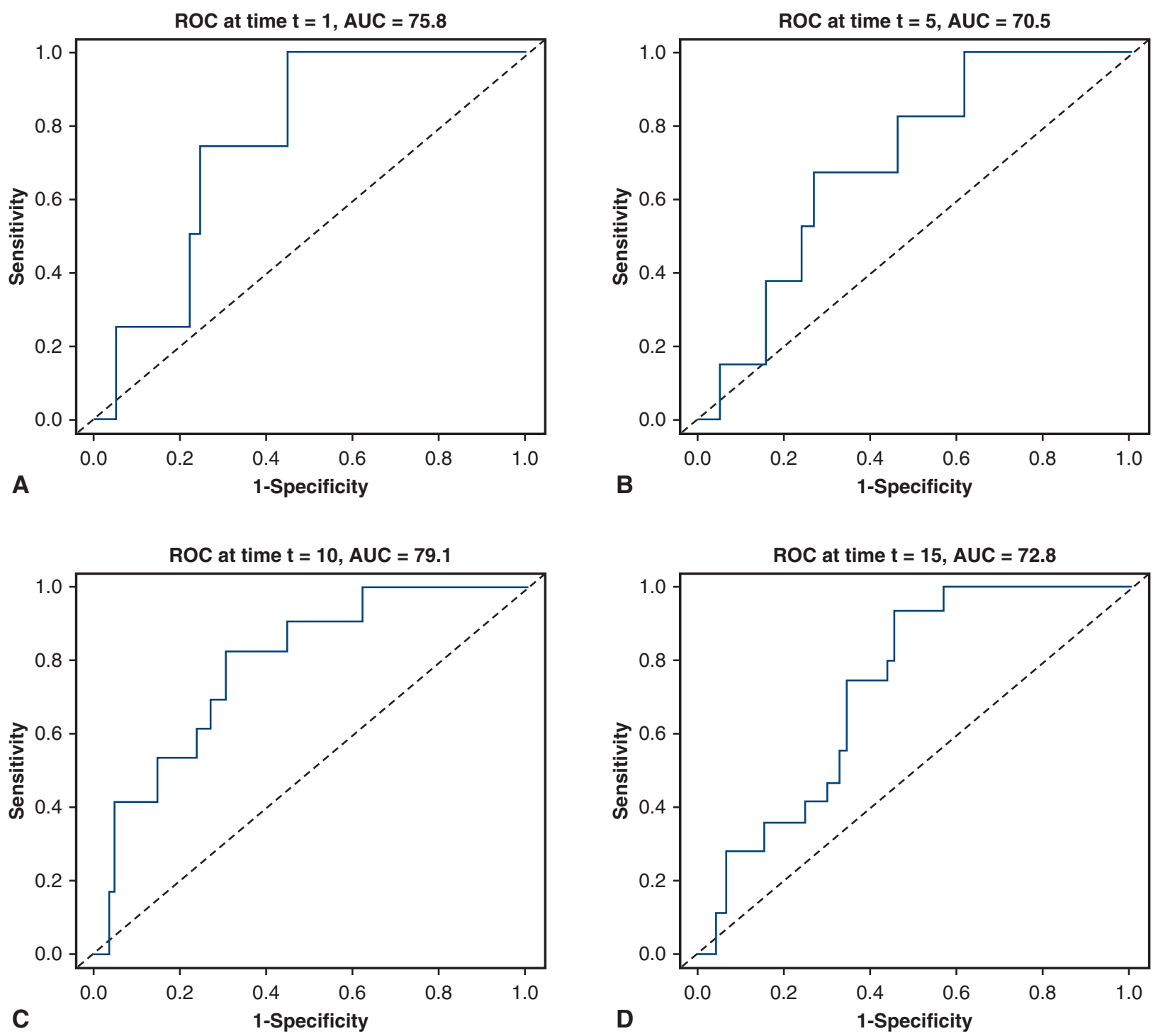

FIGURE E2. Time-dependent receiver operating characteristics $(R O C)$ analyses of postoperative false lumen to true lumen ratio (FL/TL ratio) for significant aortic regurgitation (AR). A, At 1 year, area under the curve (AUC) of 0.758. B, At 5 years, AUC of 0.705. C, At 10 years, AUC of 0.791 . D, At 15 years, AUC of 0.728 . These results suggest that the FL/TL ratio is a reliable marker for predicting significant AR at each time point. 

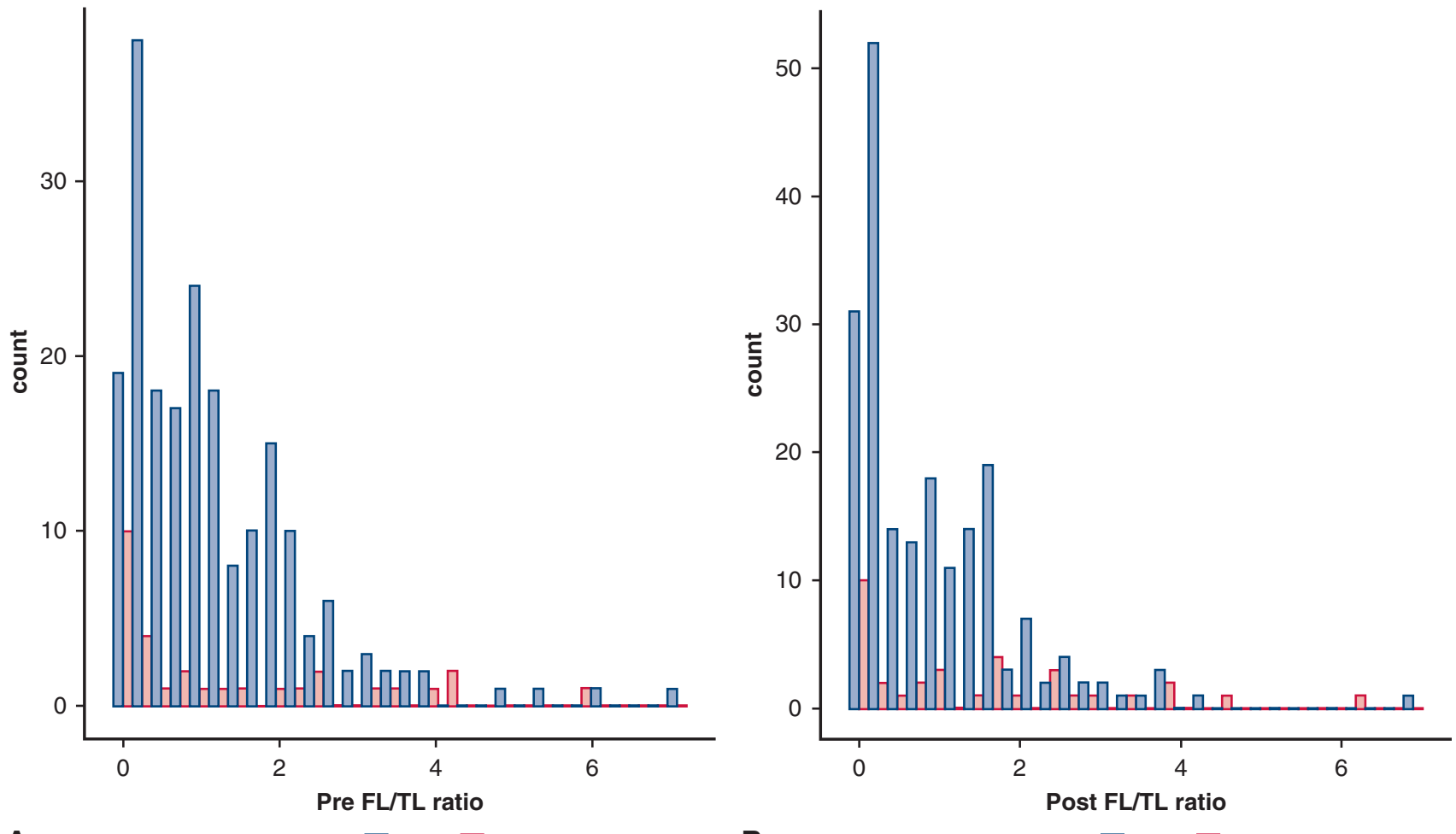

\section{A} Group $\square$ AAR $\square R$

B Group $\square$ AAR $\square$ RR

FIGURE E3. Histogram of the preoperative (A) and postoperative (B) false lumen to true lumen ratios (FL/TL ratios) in the 2 groups. The postoperative ratio in the ascending aortic replacement $(A A R)$ group was lower than that in the root replacement $(R R)$ group, whereas the preoperative ratio was similar in both groups.

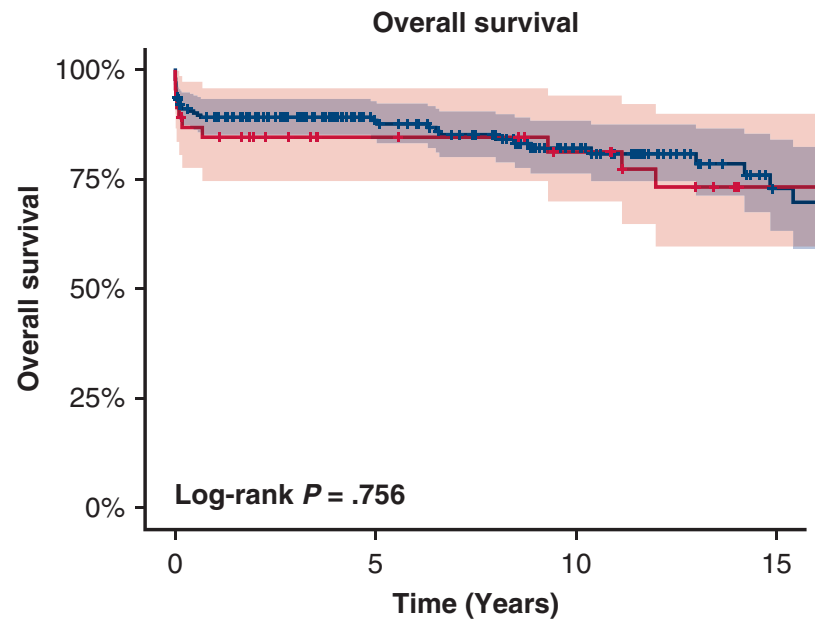

Number at risk

$\begin{array}{lcccc}\text { AAR } & 225 & 115 & 66 & 23 \\ \text { RR } & 46 & 28 & 23 & 12 \\ & & \text { Group } & + \text { AAR }+ \text { RR } & \end{array}$

FIGURE E4. Kaplan-Meier survival curves for the ascending aortic replacement $(A A R)$ versus root replacement $(R R)$ group at 15 years. There was no significant difference between the AAR and RR groups. Shaded area represents $95 \%$ confidence interval. 
TABLE E1. Change over time in postoperative aortic regurgitation grade by ordinal mixed-effects model*

\begin{tabular}{lcc}
\hline Correlate & Coefficient \pm standard error & $\boldsymbol{P}$ value \\
\hline Duration, y & $0.139 \pm 0.023$ & $<.001$ \\
Intercept 0 & $0.729 \pm 0.198$ & $<.001$ \\
Intercept 1 & $2.805 \pm 0.244$ & $<.001$ \\
Intercept 2 & $4.437 \pm 0.296$ & $<.001$ \\
\hline
\end{tabular}

*This model includes the variable of follow-up duration as a fixed effect and a random intercept. With increased follow-up duration, a higher aortic regurgitation grade $\left(\exp ^{0.139}=1.149\right)$ was highly possible.

TABLE E2. Change over time in postoperative aortic regurgitation (AR) grade by multinomial ordinal mixed-effects model

\begin{tabular}{|c|c|c|c|c|}
\hline \multirow[b]{2}{*}{ Variable* } & \multicolumn{2}{|l|}{$\begin{array}{r}\text { Unadjusted } \\
\end{array}$} & \multicolumn{2}{|l|}{ Adjusted $†$} \\
\hline & Coefficient \pm standard error & $P$ value & Coefficient \pm standard error & $P$ value \\
\hline Duration (y) & $0.139 \pm 0.023$ & $<.001$ & $0.137 \pm 0.022$ & $<.001$ \\
\hline Age & $0.033 \pm 0.013$ & .013 & $0.034 \pm 0.013$ & .008 \\
\hline Male sex & $-0.718 \pm 0.336$ & .033 & $-0.420 \pm 0.303$ & .165 \\
\hline Hypertension & $-0.069 \pm 0.399$ & .863 & & \\
\hline Marfan syndrome & $0.499 \pm 0.896$ & .578 & & \\
\hline Pre-AR grade $\geq 3+$ & $3.019 \pm 0.388$ & $<.001$ & $2.297 \pm 0.350$ & $<.001$ \\
\hline Post-AR grade $\geq 2+$ & $3.870 \pm 0.478$ & $<.001$ & $2.982 \pm 0.446$ & $<.001$ \\
\hline Sinus of Valsalva & $0.125 \pm 0.027$ & $<.001$ & $0.082 \pm 0.024$ & .001 \\
\hline False/true lumen ratio & $0.006 \pm 0.004$ & .098 & $0.284 \pm 0.148$ & .055 \\
\hline
\end{tabular}

*In the unadjusted univariate model, a variable with $P<.1$ was included in the adjusted multivariate model. $\dagger$ The adjusted multivariate model showed that the predictors for increasing AR grade over time was longer duration, older age, higher preoperative AR (grade $\geq 3+$ ), higher postoperative AR (grade $\geq 2+$ ), and higher root diameter. The false to true lumen ratio was also an associated predictor for increasing AR grade over time. 
TABLE E3. Clinical information of patients who were diagnosed with Marfan syndrome after ascending aortic replacement surgery

\begin{tabular}{|c|c|c|c|c|c|c|c|c|c|c|}
\hline \multirow[b]{2}{*}{ Patient } & \multirow[b]{2}{*}{ Sex/age $(y)$} & \multicolumn{3}{|c|}{ Aortic root diameter $(\mathrm{mm})$} & \multicolumn{3}{|c|}{ AR grade } & \multirow[t]{2}{*}{$\begin{array}{c}\text { Time to } \\
\text { progressive } \\
\mathbf{A R}(\mathbf{y})^{*}\end{array}$} & \multirow[t]{2}{*}{$\begin{array}{c}\text { Time to root } \\
\text { reoperation }(\mathbf{y}) \dagger\end{array}$} & \multirow[t]{2}{*}{ Indication for root reoperation } \\
\hline & & Pre & Post & Last & $\overline{\text { Pre }}$ & Post & $\overline{\text { Last }}$ & & & \\
\hline 1 & Female/32 & 48.0 & 45.0 & 93.6 & 0 & 0 & 3 & 17.0 & 17.1 & Severe AR, root aneurysm \\
\hline 2 & Male/24 & 57.0 & 50.3 & 92.0 & 0 & 0 & 4 & 8.9 & 9.0 & Severe AR, root aneurysm \\
\hline 3 & Male/34 & 49.3 & 46.0 & 64.0 & 3 & 0 & 3 & 6.9 & 7.1 & Severe AR, root aneurysm \\
\hline 4 & Female/34 & 42.5 & 39.0 & 56.0 & 4 & 0 & 4 & 10.8 & 10.9 & Severe AR, annuloaortic ectasia \\
\hline 5 & Female/54 & 54.7 & 41.0 & 55.0 & 3 & 2 & 3 & 2.4 & 2.6 & Severe AR, annuloaortic ectasia \\
\hline 6 & Female/30 & 36.4 & 34.5 & No data & 0 & 0 & 0 & & & \\
\hline 7 & Male/36 & 50.2 & 47.9 & 57.0 & 0 & 0 & 0 & & & \\
\hline 8 & Male/38 & 48.4 & 44.0 & 44.0 & 0 & 0 & 0 & & 0.9 & Proximal pseudoaneurysm \\
\hline
\end{tabular}

